\title{
EVALUASI KUALITAS PENERANGAN RUANG KULIAH FAKULTAS TEKNIK UNIVERSITAS PGRI PALEMBANG
}

\author{
Panji Anugrah Pratama ${ }^{1}$, Nita Nurdiana ${ }^{2}$ \\ 1,2 Program Studi Teknik Elektro Fakultas Teknik Universitas Palembang \\ panjianugrah12345@gmail.com ${ }^{1}$ nurdiana78@ univpgri-palembang.ac.id $^{2}$
}

\begin{abstract}
ABSTRAK Penglihatan tidak menjadi lebih baik hanya dari jumlah atau kuantitas cahaya tetapi juga dari kualitasnya. Kuantitas dan kualitas pencahayaan yang baik di tentukan dari tingkat refleksi cahaya dan tingkat rasio pencahayaan pada ruangan. Pemasangan penerangan listrik yang tidak sesuai dengan standar penerangan yang berlaku, akan menimbulkan kerugian bagi dosen dan mahasiswa. Ruang Kuliah di Fakultas Teknik Universitas PGRI Palembang merupakan ruang dengan aktifitas utama mengajar,belajar,baca dan menulis. Menurut Standar Nasional Indonesia (SNI), Kuat penerangan minimum yang diharapkan untuk Ruang Kuliah adalah 250 Lux. Dalam hal ini penulis melakukan penelitian terhadap pencahayaan yang ada pada ruang kuliah Fakultas Teknik Universitas PGRI Palembang yang bertujuan untuk mengetahui kuat penerangan di ruang kuliah Fakultas Teknik PGRI Palembang, dan untuk mengetahui standar atau tidaknya pencahayaan di ruang kuliah Fakultas Teknik PGRI Palembang yang sudah di tetapkan SNI 03-6575-2001. Dari data hasil pengukuran disalah satu ruang kuliah Fakultas Teknik Universitas PGRI Palembang, ruang R.D.Lt.1,R.1 sebesar 90,4658 lux, untuk hasil pengukuran di waktu pagi 49,46667 lux dan di waktu siang menunjukan 106,4889 lux
\end{abstract}

\section{Kata kunci : Kualitas Pencahayaan, Kuat Penerangan, Pencahayaan Ruang Kuliah.}

\begin{abstract}
Sight is not improved only by the number or quantity of light but also by its quality. The quantity and quality of good lighting was determined by the light reflection level and the lighting ratio in the room. Inappropriate exposure to light standards can be harmful to teachers and students. The college of engineering at PGRI Palembang University is a room with key activities of teaching, studying, reading and writing. By indonesia's national standards (SNI), the strong minimum illumination expected for college space was 250 lux. In this case the writer did research on lighting in the college of engineering at PGRI Palembang University school of engineering aimed at strong know ledge of light in the PGRI Palembang school of engineering, and to find out the standards or not of lighting in the existing PGRI Palembang school of engineering room 03-6575-2001. From the data of the results of the one study of engineering at PGRI Palembang University, the R.D,Lt.1,R.1 in 90,4658 lux, for measurements at 49,46667 lux in the morning 106,4889 lux.
\end{abstract}

Keyword : The Quality of Lighting, lumination, Lecture Room Lighting.

\section{PENDAHULUAN}

Pencahayaan tidak menjadi lebih baik hanya dari kuantitas cahaya atau dari jumlah cahaya tetapi juga dari kualitasnya. Kualitas dan kuantitas pencahayaan yang baik di tentukan dari tingkat rasio cahaya dan tingkat refleksi pencahayaan pada ruangan.

Pemasangan penerangan listrik yang tidak sesuai dengan standar penerangan, akan menimbulkan kerugian bagi dosen dan mahasiswa. Kerugian yang akan terjadi akibat pemasangan penerangan listrik yang tidak mencapai standar misalnya mempengaruhi pusat syaraf penglihatan di otak. Jadi penerangan listrik, selain mempunyai manfaat yang besar untuk memenuhi kebutuhan manusia, juga dapat menimbulkan kerugian 
apabila pemasangan tidak sesuai dengan standar yang berlaku.

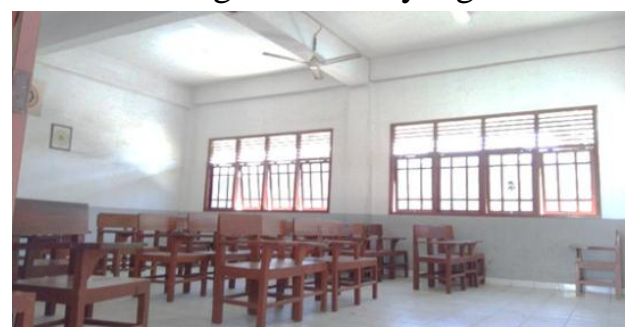

Gambar 1. Ruang Kuliah Fakultas Teknik Universitas PGRI Palembang

Ruang Kuliah di Fakultas Teknik Universitas PGRI Palembang merupakan ruang dengan aktifitas utama mengajar,belajar,baca dan menulis. Menurut Standar Nasional Indonesia SNI 2001 [3] kuat penerangan minimum yang diharapkan untuk Ruang Kuliah adalah 250 Lux. Berdasarkan hal tersebut, maka sangat perlu untuk melakukan penelitian tentang kuat pencahayaan di ruang kuliah karena pencahayaan sangat berpengaruh terhadap kesehatan mata dosen maupun mahasiswa dan derajat kelelahan mata serta secara tidak langsung mempengaruhi tingkat konsentrasi mahasiswa terhadap perkuliahan atau proses belajar dan mengajar

\section{TINJAUAN PUSTAKA}

\section{Penerangan Dalam Ruangan}

Ketika merencanakan penerangan di dalam ruangan yang harus diperharikan yaitu arah pencahayaan sumber penerangan dan kuat penerangan warna cahaya yang diperlukan. Kuat penerangan akan menghasikan luminasi karena pengaruh pantulan dinding maupun lantai ruangan. Kuat penerangan dikategorikan menjadi 6 yaitu :

1. Penerangan Ekstra Rendah, dibawah 50 lx.

2. Penerangan Rendah, dibawah 150 lx.

3. Penerangan Sedang, 150 hingga 175 lx.

4. Penerangan Tinggi :
a. Penerangan Tinggi I, $200 \mathrm{~lx}$.
b. Penerangan Tinggi II, $300 \mathrm{~lx}$.
c. Penerangan Tinggi III, $450 \mathrm{~lx}$.

5. Penerangan Sangat Tinggi, 700 lx.

6. Penerangan Exstra Tinggi, diatas 700 lx.

Pancaran cahaya harus mendapatkan perhatian pada saat perencanaan penerangan disamping warna yang dihasilkan sumber cahaya. Sumber cahaya adalah satuan penerangan lengkap yang terdiri dari lampu beserta perlengkapan aplikasi yang lain.

\section{Penerangan Ruang Kuliah}

Pancaran cahaya perlu mendapatkan perhatian pada saat perencanaan penerangan disamping warna yang dihasilkan sumber cahaya. Sumber cahaya adalah satuan penerangan lengkap yang terdiri dari lampu beserta perlengkapan aplikasi yang lain.

Aspek pencahayaan pada ruang kuliah menentukan kenyamanan bagi pengguna bergantung pada kualitas dan kuantitas sumber cahaya. Cahaya terkadang dapat menyilaukan, bahkan terkadang dapat menimbulkan hal-hal yang tidak diinginkan seperti ; kelelahan mata dengan berkurangnya daya dan efisiensi kerja, kelelahan mental, keluhan-keluhan pegal di sekitar daerah mata dan sakit mata, keluhan penglihatan, bahkan dapat meningkatkan kecelakaan. 
Dengan adanya ketetapan standar pencahayaan pada ruang kuliah ini dapat membuat keseragaman pencahayaan antara ruang kuliah satu dengan yang lainnya, dan juga agar pencahayaan yang dibutuhkan oleh pengguna ruang kuliah cukup, tidak berlebihan ataupun kekurangan. Jadi sangatlah penting bagi perancang bangunan untuk merangcangkan sistem pencahayaan yang memadai dan sesuai dengan standar yang telah ditetapkan untuk ruang kuliah, baik alami maupun buatan.

Penerangan pada suatu bidang kerja atau suatu ruangan haruslah diusahakan cukup dan memadai untuk faktor psikologi orang yang bekerja pada ruangan tersebut, disamping itu syaratsyarat penerangan itu sendiri bergantung dari :

a. Sifat atau klasifikasi tempat (baik gedung maupun ruangan) dimana suatu pekerjaan dilakukan.

b. Lamanya waktu kerja dari pekerjaan yang dilakukan.

c. Jenis dan sifat pekerjaan yang dilakukan.

Berdasarkan hal tersebut diatas, maka telah ditentukan standar penerangan sebagai syarat yang sesuai dengan berbagai keperluan, dan untuk tingkat pencahayaan minimum dan renderasi warna yang direkomendasikan untuk berbagai fungsi ruangan.

Tabel 1. Tingkat Pencahayaan Minimum dan Renderasi Warna yang Direkomendasikan

\begin{tabular}{|c|c|c|c|}
\hline Fungsi Ruangan & $\begin{array}{c}\text { Tingkat } \\
\text { Pencahayaan } \\
\text { (Lux) }\end{array}$ & $\begin{array}{c}\text { Kelompok } \\
\text { Renderasi } \\
\text { Warna } \\
\end{array}$ & Keterangan \\
\hline \multicolumn{4}{|c|}{ Rumah Tinggal : } \\
\hline Terteras & 60 & 1 atau 2 & \\
\hline Ruang Tamu & $120 \sim 250$ & 1 atau 2 & \\
\hline Ruang Makan & $120 \sim 250$ & 1 atau 2 & \\
\hline Ruang Kerja & $120 \sim 250$ & 1 & \\
\hline Kamar Tidur & $120 \sim 250$ & 1 atau 2 & \\
\hline Kamar Mandi & 250 & 1 atau 2 & \\
\hline Dapur & 250 & 1 atau 2 & \\
\hline Garasi & 60 & 3 atau 4 & \\
\hline \multicolumn{4}{|c|}{ Perkantoran : } \\
\hline Ruang Direktur & 350 & 1 atau 2 & \\
\hline Ruang Kerja & 350 & 1 atau 2 & \\
\hline Ruang Komputer & 350 & 1 atau 2 & $\begin{array}{l}\text { Gunakan armature berkisi untuk mencegah silau } \\
\text { akibat pantulan layar monitor }\end{array}$ \\
\hline Ruang Rapat & 350 & 1 atau 2 & \\
\hline Ruang Gambar & 750 & 1 atau 2 & Gunakan pencahayaan setempat pada meja gambar \\
\hline Gudang Arsip & 150 & 3 atau 4 & \\
\hline Ruang Arsip Aktif & 300 & 1 atau 2 & \\
\hline \multicolumn{4}{|c|}{ Lembaga Pendidikan : } \\
\hline $\begin{array}{lll}\text { Ruang } & \text { Kelas } \quad / \\
\text { Kuliah } & & \end{array}$ & 250 & 1 atau 2 & \\
\hline Perpustakaan & 300 & 1 atau 2 & \\
\hline Laboratorium & 500 & 1 & \\
\hline Ruang Gambar & 750 & 1 & Gunakan pencahayaan setempat pada meja gambar \\
\hline Kantin & 200 & 1 & \\
\hline
\end{tabular}

Sumber : SNI 03-6575-2001

Disamping perlu diketahui tampak warna suatu lampu, juga dipergunakan suatu indeks yang menyatakan apakah warna obyek tampak alami apabila diberi cahaya lampu tersebut. Nilai maksimum secara teoritis dari indeks renderasi warna adalah 100 .

\section{Sistem Penerangan}


Sistem penernagan buatan di dalam gedung merupakan pencahayaan yang sengaja dibuat untuk menerangai ruangan-ruangan yang gelap pada saat malam hari maupun siang hari bila saat penerangan alami atau cahaya matahari tidak memungkinkan untuk menerangi ruangan tersebut [2] Penerangan alami tidak dapat memenuhi persyaratan bagi penerangan ruangan (dalam bangunan) ini disebabkan oleh ruangan yang luas, lubang cahaya yang tidak efektif, cuaca di luar mendung/hujan, waktu malam hari dan sebagainya.

Kualitas peneranganbuatan yang baik pada suatu ruang sangat mempengaruhi hasil dari aktifitas yang akan di lakukan. Maka dari itu penerangan yang baik harus benar-benar di rencanakan. Hal-hal yang perlu diperhatikan sejak awal perancangan bangunan yaitu :

a. Apakah penerangan buatan digunakan tersendiri atau sebagai penunjang/pelengkap penerangan alami.

b. Variasi fluks cahaya dan Distribusi cahaya yang diperlukan.

c. Berapa itensitas penerangan yang diperlukan.

d. Derajat kesilauan brightness dari keseluruhan lingkungan visual.

e. Arah cahaya yang diperlukan.

f. Warna cahaya yang digunakan didalam gedung dan efek-efek warna yang diinginkan.

Sebagian cahaya yang ditangkap oleh mata, tidak langsung dari sumber cahaya, tetapi di pantulkan oleh lingkungan. Berdasarkan pembagian fluks cahaya dan armature yang digunakan, maka sistem penerangan [2][6] dibedakan menjadi :

1. Sistem Penerangan Langsung (Direct Lighting)

Pada sistem langsung, 90-100\% dari cahaya diarahkan langsung kepada permukaan yang diterangi. Sistem ini paling efektif dalam menyediakan penerangan, namun juga mengakibatkan adanya bayangan yang mengganggu, serta mengakibatkan terjadinya kesilauan karena penyinaran lampu maupun karena pemantulan sinar lampu. Langit-langit dinding dan objek di dalam ruangan perlu diberi warna yang cerah supaya tampak menyegarkan. Efisiensi penerangan langsung yang baik, cahaya dari sumber cahaya seluruhnya di arahkan ke bidang kerja yang harus diberi sistem penerangan, langit-langit hampir tidak ikut berperan, tapi sistem ini mengakibatkan bayang yang tajam. Kelemahan ini dapat di kurangi dengan menggunakan sumber cahaya bentuk tabung (TL). Sistem penerangan ini digunakan di ruang-ruang yang tinggi, misalnya bengkel, pabrik dan penerangan luar. Armatur yang di gunakan adalah pancaran terbatas.

2. Sistem Penerangan Semi Langsung (Semi Direct Lighting)

Pada sistem semi langsung, 60-90\% dari cahaya diarahkan langsung kepada permukaan yang perlu diterangi, sedang selebihnya menerangi serta dipantulkan oleh langit-langit dan dinding. Sistem iluminasi ini dapat menutupi kekurangan dari sistem iluminasi langsung di atas. Efisiensi penerangan ini sudah cukup baik dibandingkan dengan sistem penerangan langsung, pembentukan bayang-bayang dan kilauan agak berkurang. Sejumlah cahaya kecil yang dipancarkan ke atas, karena itu kesan mengenai ukuran ruangnya menjadi lebih baik. Seolaholah langit-langitnya lebih tinggi. Sistem penerangan ini digunakan di gedung-gedung ibadah, untuk tangga dalam rumah, gang dan sebagainya.

3. Sistem Penerangan Tak Langsung (Indirect Lighting)

Pada sistem tidak langsung, 90-100\% cahaya diarahkan ke langit-langit dan dinding bagian atas untuk dipantulkan kemudian menerangi seluruh ruangan berupa cahaya diffuse. Warna langitlangit dan dinding-dinding ini harus terang. Bayang-bayang hampir tidak ada lagi. Penerangan ini langsung antara lain digunakan di ruang baca, tulis dan untuk pekerjaan-pekerjaan halus lainnya. 


\section{Sistem Penerangan Semi Tak Langsung (Semi Indirect Lighting)}

Pada sistem semi tidak langsung, 60-90\% dari cahaya diarahkan ke langit-langit dan dindingdinding bagian atas, dan sisanya ke bawah. Masalah bayangan praktis tidak ada, dan kesilauan dapat dikurangi. Karena itu langit-langit dan dinding-dinding ruangan harus diberi warna terang. Sistem penerangan ini digunakan di rumah-rumah sakit, di ruang baca, toko-toko dan di kamar tamu.

5. Sistem Penerangan Diffus (General Diffuse Lighting)

Di dalam sistem iluminasi ini termasuk sistem direct-indirect yang memancarkan setengah cahaya ke bawah dan ke atas. Masalah-masalah bayangan dan kesilauan masih terdapat pada sistem iluminasi ini. Efisiensi penerangan diffuse lebih baik dari sistem penerangan langsung dan sistem penerangan semi langsung, sebagian dari cahaya sumber-sumber cahaya diarahkan kedinding dan ke langit-langit. Permukaan bayangan-bayangan dan kilauan bayang berkurang. Penerangan diffuse digunakan di ruang-ruang sekolah, di ruangan-ruangan kantor dan tempat kerja.

\section{Kriteria Teknik Penerangan}

Dalam instalasi penerangan untuk menentukan jumlah lampu yang dibutuhkan pada suatu ruangan tergantung pada :

a. Bentuk penggunaan suatu ruangan, setiap macam bentuk penggunaan ruangan mempunyai kebutuhan kuat penerangan (lumen per meter persegi atau Lux).

b. Keadaan dinding dan lingkungannya dari ruang tersebut.

c. Ukuran ruang tersebut, semakin luas suatu ruangan yang akan diterangi maka semakin banyak juga penggunaan lampunya.

d. Jenis lampu yang akan dipakai dan sistem penerangan yang digunakan.

Dalam merencanakan teknik pencahayaan ada 6 kriteria yang harus diperhatikan agar mendapatkan pencahayaan yang baik [6] . Kriteria-kriteria tersebut adalah

a. Kuat Penerangan atau Intensitas Penerangan

Intensitas penerangan atau Kuat penerangan yaitu suatu ukuran untuk terangnya suatu benda. Intensitas penerangan sebagian besar ditentukan oleh jumlah cahaya total yang dipancarkan oleh sumber cahaya (intensitas cahaya) setiap detik yang jatuh pada suatu permukaan bidang tertentu. Untuk perhitungan instalasi penerangan di suatu ruangan perlu diperhatikan faktor refleksi dari dinding, cahaya dari langit-langit, cahaya dari lantai dan benda-benda yang berada dalam ruangan tersebut.

b. Arah Pencahayaan dan Pembentukan Bayangan

Arah pencahayaan sangat mempengaruhi pembentukan bayangan. Arah pencahayaan dan pembentukan bayangan dapat menghasilkan kesan terhadap benda yang kita lihat. Pembagian/distribusi pencahayaan dan pengaturan susunan armatur lampu mempengaruhi arah pencahayaan. Bayangan yang terlalu kuat atau tanpa bayangan sama sekali hendaknya dihindarkan. Ruangan tanpa bayangan menimbulkan kesan monoton atau membosankan selain mempersulit penglihatan.

c. Distribusi Kepadatan Cahaya

Kepadatan cahaya atau iluminasi adalah ukuran kepadatan radiasi cahaya pembatasan cahaya agar tidak menyilaukan mata. Untuk membatasi cahaya agar tidak menyilaukan mata dapat dilakukan dengan teknik pemasangan lampu yang tidak berada pada sudut pandang $\left(45^{\circ}\right)$ dan untuk cahaya pembuatan dapat dihindari dengan memakai armatur yang dilengkapi dengan louvre atau optic mirror. 


\section{d. Kondisi dan Iklim Ruangan}

Iklim ruangan sangat mempengaruhi pencahayaan di dalam ruangan tersebut. Hal ini tergantung pada beberapa parameter, yaitu pencahayaan warna ruang secara teknik pengaturan udara termasuk teknik pengaturan temperature ruangan. Oleh karena itu dalam merencanakan teknik pencahayaan pada ruang kerja perlu diperhatikan bahwa pencahayaan harus memberikan kondisi yang nyaman, menyenangkan, dan aman.

e. Warna Cahaya dan Refleksi Warna

Warna benda yang dilihat adalah relative karena tergantung pada pencahayaan. Di dalam teori teknik penerangan warna dinding dan warna langit sangat menentukan terang atau tidaknya sebuah lampu yang dipasang pada suatu ruangan. Jadi dinding yang bewarna putih bersih akan memberikan hasil penerangan lebih terang dari pada dinding dan langit yang bewarna gelap atau dengan kata lain putih dapat memantulkan kembali sinar lampu.

\section{METODE PENELITIAN}

Tahapan-tahapan penelitian yang akan dilakukan sebagai berikut :

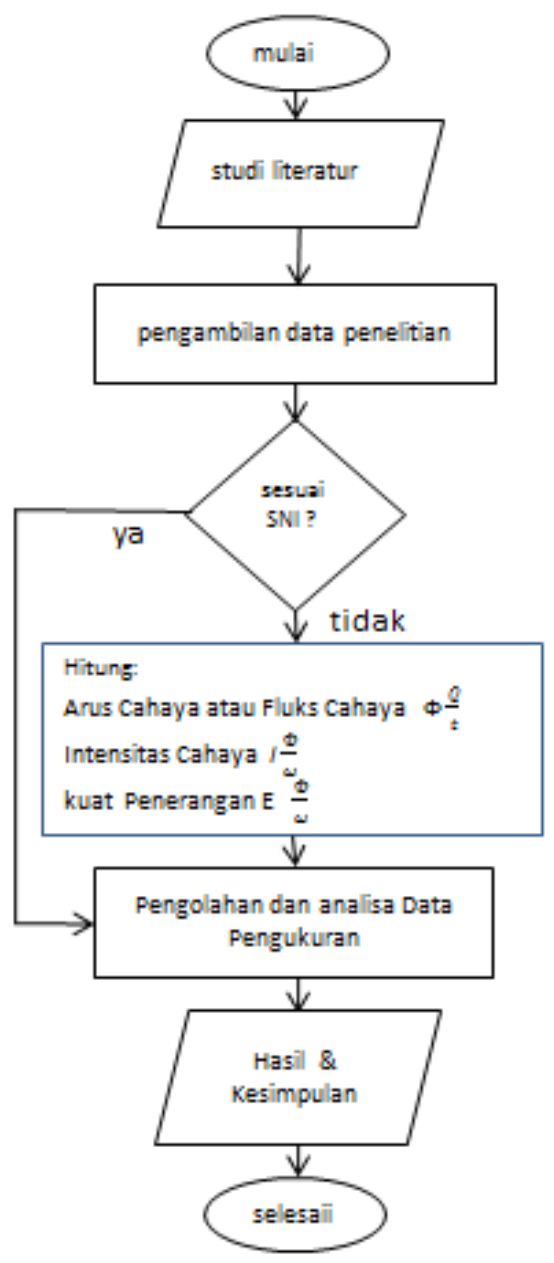

Gambar 2. Tahapan Penelitian

Penelitian Evaluasi Kualitas Penerangan Ruang Kuliah Fakultas Teknik Universitas PGRI Palembang dilakukan dengan metode eksprimental dengan langkah-langkah : 
1. Pengumpulan data-data mengenai penelitian dan pengukuran.

2. Surve lokasi penelitian dan pengukuran dimensi ruang kelas, jenis lampu serta intensitas penerangan pada lokasi penelitian

3. Peralatan dan Alat Ukur intensitas peneragan lux meter dan meteran.

4. Penentuan Titik pengamatan menggunakan lux meter

\section{Penentuan Titik Pengamatan Dalam Penelitian}

Di dalam pengamatan dan penelitian di setiap ruang kuliah fakultas teknik Universitas PGRI Palembang di tentukan 6 titik, yaitu :

1. Titik 1 (Meja Dosen)

2. Titik 2 (Papan Tulis)

3. Titik 3,4,5,dan 6 (Kursi Mahasisawa)
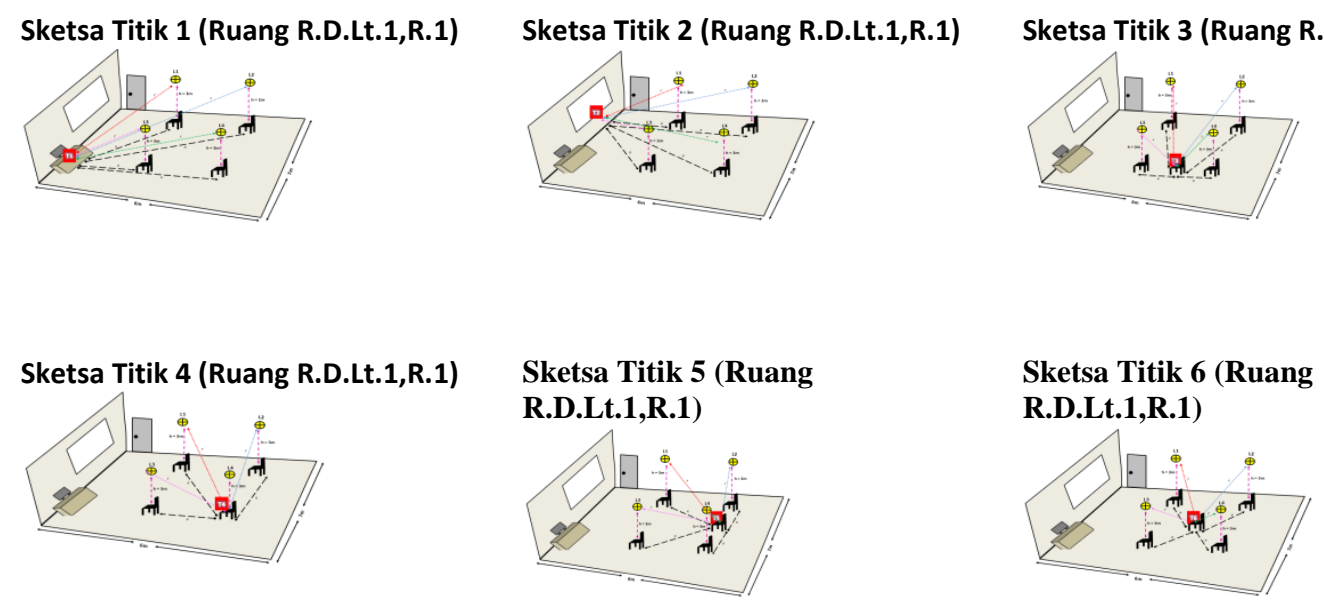

Gambar 3. sketsa titik Ukur Pengamatan

\section{Penentuan Arus Cahaya Atau Fluks Cahaya}

Arus cahaya atau fluks cahaya (diukur dengan lumen) [2][4] adalah banyak cahaya yang dipancarkan ke segala arah oleh sebuah sumber cahaya persatuan waktu (bahasa perdetik). Arus cahaya atau fluks cahaya dapat ditentukan dengan persamaan :

$\Phi=\frac{Q}{t}$

Dimana :

$\Phi=$ Fluks Cahaya (Lumen)

$\mathrm{Q}=$ Energi Cahaya (Lumen detik)

$\mathrm{t}=$ Waktu (detik)

\section{Penentuan Intensitas Cahaya}

Intensitas cahaya adalah fluks cahaya per satuan sudut ruang yang dipancarkan ke suatu arah tertentu. Intensitas cahaya dapat ditentukan dengan persamaan :

$I=\frac{\Phi}{\omega} \quad$ Atau $\quad \Phi=I \mathrm{x} \omega$

Dimana :

$I=$ Intensitas Cahaya (Candela)

$\Phi=$ Fluks Cahaya (Lumen) 
$\omega=$ Sudut Ruang

\section{Intensitas Penerangan}

Intensitas penerangan atau iluminasi di suatu bidang [4] adalah fluks cahaya yang jatuh pada $1 \mathrm{~m}^{2}$ dari bidang tersebut. Intensitas penerangan atau iluminasi dapat ditentukan dengan persamaan :

$\mathrm{E}_{\text {rata-rata }}=\frac{\Phi}{A}$

Dimana :

$\mathrm{E}_{\text {rata-rata }}=$ Intensitas penerangan atau iluminasi (lux)

$\Phi \quad=$ Fluks cahaya (lumen)

A $\quad=$ Luas permukaan bidang $\left(\mathrm{m}_{2}\right)$

\section{PEMBAHASAN}

\section{Sistem Penerangan Yang Digunakan}

Ruang Kuliah Fakultas Teknik Universitas PGRI Palembang menggunakan sistem penerangan langsung dan menggunakan dua sumber penerangan yaitu penerangan alami (cahaya matahari) dan penerangan buatan (lampu). Di bawah ini merupakan gambar tata ruang dan tata letak sumber penerangan Ruang Kuliah Fakultas Teknik Universitas PGRI Palembang dapat dilihat pada gambar 4.2

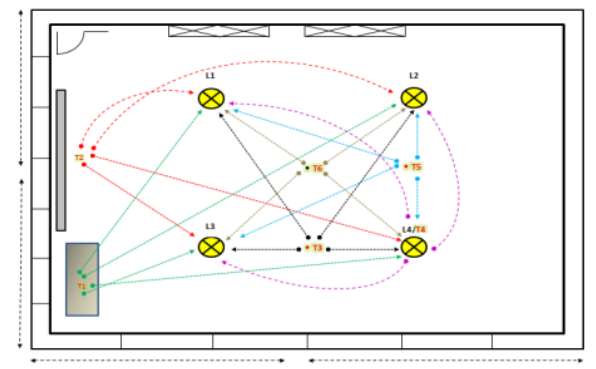

Gambar 4. Denah titik Pengukuran

Tabel 2. Data Ruang Kuliah Fakultas Teknik Universitas PGRI Palembang

\begin{tabular}{lcccccccc}
\hline \multirow{2}{*}{ No } & \multirow{2}{*}{ Ruangan } & \multicolumn{7}{c}{ Data Ruangan } \\
\cline { 3 - 7 } & $\mathrm{P}(\mathrm{m})$ & $\mathrm{L}(\mathrm{m})$ & $\mathrm{T}(\mathrm{m})$ & $\boldsymbol{\Phi} / 1$ & $\Sigma$ arm & $\boldsymbol{\Sigma} \mathrm{L}$ & \multirow{2}{*}{ Jenis Lampu } \\
\hline 1 & R.D.Lt.1,R.1 & 6 & 7 & 4 & $8 \times 1080$ & 4 & $2 \times 4$ & TLD \\
\hline 2 & R.D.Lt.1,R.2 & 6,80 & 7 & 4 & $8 \times 1080$ & 4 & $2 \times 4$ & TLD \\
\hline 3 & R.D.Lt.1,R.3 & 7,90 & 7 & 4 & $1 \times 1044$ & 4 & $1 \times 4$ & Essential \\
\hline 4 & R.G.Lt.1,R.3 & 8,15 & 6,9 & 4 & $1 \times 1044$ & 4 & $1 \times 4$ & Essential \\
\hline 5 & R.G.Lt.1,R.4 & 8,10 & 6,9 & 4 & $1 \times 1044$ & 4 & $1 \times 4$ & Essential \\
\hline
\end{tabular}

\section{Pengukuran Iluminasi}

Pengukuran iluminasi [2][3] merupakan suatu cara yang dilakukan untuk mengetahui seberapa besar kuat penerangan yang ada pada suatu tempat agar diketahui besar kecilnya nilai intensitas cahayanya. Alat yang digunakan untuk mengukur kuat penerangan adalah light meter atau lux meter. Pengukuran kuat penerangan Ruang Kuliah Fakultas Teknik Universitas PGRI Palembang dilakukan pada Pagi dan Siang hari dengan ketentuan pukul pagi 07:30-09:00, siang 
10:00-11:00 yang dilakukan dengan keadaan lampu menyala. Pengukuran ini dilakukan pada titiktitik pengamatan pada Ruang Kuliah Fakultas Teknik Universitas PGRI Palembang.

Tabel 3. Hasil Pengukuran Intensitas Cahaya Ruang Kuliah Fakultas Teknik

Universitas PGRI Palembang

\begin{tabular}{|c|c|c|c|c|c|c|c|c|c|c|c|}
\hline \multirow[t]{2}{*}{ Ruang Kuliah } & \multicolumn{3}{|c|}{$\begin{array}{l}\text { Dimensi } \\
\text { (meter/m) }\end{array}$} & \multirow{2}{*}{\multicolumn{2}{|c|}{$\begin{array}{c}\text { Waktu } \\
\text { Pengukuran } \\
\text { (AM) }\end{array}$}} & \multicolumn{6}{|c|}{ Kuat Penerangan } \\
\hline & $\mathbf{P}$ & $\mathrm{L}$ & $T$ & & & $\mathrm{~T} 1$ & T2 & T3 & T4 & T5 & T6 \\
\hline \multirow{2}{*}{ R.D.Lt.1,R.1 } & \multirow{2}{*}{6} & \multirow{2}{*}{7} & \multirow{2}{*}{4} & Pagi & $7: 30$ & 46,2 & 51,2 & 49,9 & 50 & 47,7 & 50,6 \\
\hline & & & & Siang & $10: 00$ & 105,1 & 105,9 & 107,4 & 107,5 & 105,5 & 107,5 \\
\hline \multirow{2}{*}{ R.D.Lt.1,R.2 } & \multirow{2}{*}{6,8} & \multirow{2}{*}{7} & \multirow{2}{*}{4} & Pagi & $8: 00$ & 28,2 & 29,4 & 29,7 & 29,8 & 29,2 & 29,5 \\
\hline & & & & Siang & $10: 17$ & 90 & 90,2 & 90,5 & 90,5 & 90,5 & 90,7 \\
\hline \multirow{2}{*}{ R.D.Lt.1,R.3 } & \multirow{2}{*}{7.90} & \multirow{2}{*}{7} & \multirow{2}{*}{4} & Pagi & $8: 20$ & 29,2 & 28,5 & 28,4 & 28,5 & 28,4 & 28,3 \\
\hline & & & & Siang & $10: 24$ & 95,8 & 98,4 & 105,5 & 103,5 & 101,9 & 106,6 \\
\hline \multirow{2}{*}{ R.G.Lt.1,R.3 } & \multirow{2}{*}{8,15} & \multirow{2}{*}{7} & \multirow{2}{*}{4} & Pagi & $8: 50$ & 24,3 & 24,2 & 23 & 23,1 & 23,5 & 22,8 \\
\hline & & & & Siang & $10: 40$ & 99 & 99,3 & 103,3 & 103 & 102,5 & 104,5 \\
\hline \multirow{2}{*}{ R.G.Lt.1,R.4 } & \multirow{2}{*}{8.10} & \multirow{2}{*}{7} & \multirow{2}{*}{4} & Pagi & $9: 00$ & 20,4 & 20,5 & 20,5 & 20,5 & 20,4 & 20,6 \\
\hline & & & & Siang & $11: 09$ & 83,5 & 84,4 & 84,5 & 85 & 85,5 & 87,5 \\
\hline
\end{tabular}

Tabel 4. Perbandingan Hasil Kuat Penerangan

\begin{tabular}{|c|c|c|c|c|c|c|c|c|c|c|c|c|c|c|}
\hline \multirow{2}{*}{ Ruang Kuliah } & \multirow{2}{*}{ SNI } & \multicolumn{7}{|c|}{ Kuat Penerangan (Pengukuran) Lux } & \multicolumn{6}{|c|}{ Kuat Penerangan (Perhitungan) Lux } \\
\hline & & Waktu & $\mathrm{T} 1$ & $\mathrm{~T} 2$ & T3 & T4 & T5 & T6 & $\mathrm{T} 1$ & $\mathrm{~T} 2$ & T3 & $\mathrm{T} 4$ & T5 & T6 \\
\hline \multirow{2}{*}{ R.D.Lt.1,R.1 } & \multirow{2}{*}{250} & Pagi & 46.2 & 51.2 & 49.9 & 50 & 47.7 & 50.6 & \multirow{2}{*}{40.9397} & \multirow{2}{*}{43.5465} & \multirow{2}{*}{41.4658} & \multirow{2}{*}{77.4259} & \multirow{2}{*}{47.7046} & \multirow{2}{*}{59.0112} \\
\hline & & Siang & 105.1 & 105.9 & 107.4 & 107.5 & 105.5 & 107.5 & & & & & & \\
\hline \multirow{2}{*}{ R.D.Lt.1,R.2 } & \multirow{2}{*}{250} & Pagi & 28.2 & 29.4 & 29.7 & 29.8 & 29.2 & 29.5 & \multirow{2}{*}{35.2473} & \multirow{2}{*}{37.5892} & \multirow{2}{*}{38.6242} & \multirow{2}{*}{74.0143} & \multirow{2}{*}{38.6242} & \multirow{2}{*}{54.0162} \\
\hline & & Siang & 90 & 90.2 & 90.5 & 90.5 & 90.5 & 90.7 & & & & & & \\
\hline \multirow{2}{*}{ R.D.Lt.1,R.3 } & \multirow{2}{*}{250} & Pagi & 29.2 & 28.5 & 28.4 & 28.5 & 28.4 & 28.3 & \multirow{2}{*}{16.575} & \multirow{2}{*}{17.4262} & \multirow{2}{*}{16.7618} & \multirow{2}{*}{36.1861} & \multirow{2}{*}{17.5224} & \multirow{2}{*}{25.7195} \\
\hline & & Siang & 95.8 & 98.4 & 105.5 & 103.5 & 101.9 & 106.6 & & & & & & \\
\hline \multirow{2}{*}{ R.G.Lt.1,R.3 } & \multirow{2}{*}{250} & Pagi & 24.3 & 24.2 & 23 & 23.1 & 23.5 & 22.8 & \multirow{2}{*}{15.766} & \multirow{2}{*}{16.7937} & \multirow{2}{*}{15.8999} & \multirow{2}{*}{35.3636} & \multirow{2}{*}{15.2229} & \multirow{2}{*}{24.0288} \\
\hline & & Siang & 99 & 99.3 & 103.3 & 103 & 102.5 & 104.5 & & & & & & \\
\hline$R G \mid+1 R A$ & 250 & Pagi & 20.4 & 20.5 & 20.5 & 20.5 & 20.4 & 20.6 & 15.9578 & 169974 & 178935 & 356297 & 159665 & 246094 \\
\hline 10.0. & 200 & Siang & 83.5 & 84.4 & 84.5 & 85 & 85.5 & 87.5 & (1.00 & 10.0014 & 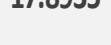 & 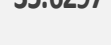 & 10.0000 & 27.0007 \\
\hline
\end{tabular}

Mengacu pada SNI 2001 [3] untuk kuat penerangan ruang kelas sebaiknya sebesar 250 lux .

Dari pengukuran dan perhitungan di setiap bidang kerja yang ada pada Ruang Kuliah Fakultas Teknik Universitas PGRI Palembang menunjukan data pengukuran intensitas di ruang Teknik R.D.Lt.1,R.1; R.D.Lt.1,R.2; R.D.Lt.1,R.3; R.G.Lt.1,R.3; R.G.Lt.1,R.4. Pada Ruang R.D.Lt.1,R.1; R.D.Lt.1,R.2 menggunakan lampu berjenis TLD (Philiph) dengan Armatur berjumlah 4 dan disetiap Armatur memiliki 2 lampu. Pada pengukuran di pagi hari pada Ruang R.D.Lt.1,R.1 di titik 1 (T1) menghasilkan 46,2 lux dan diwaktu siang 105,1 lux. Pada pengukuran di pagi hari pada Ruang R.D.Lt.1,R.2 di titik 1 (T1) menghasilkan 28,2 lux dan diwaktu siang 90 lux. Pada Ruang R.D.Lt.1,R.3; R.G.Lt.1,R.3; R.G.Lt.1,R.4 menggunakan lampu berjenis Essential (Philiph) dengan Armatur berjumlah 4 dan disetiap Armatur memiliki 1 lampu. Pada pengukuran di pagi hari pada 
Ruang R.D.Lt.1,R.3 di titik 1 (T1) menghasilkan 29,2 lux dan diwaktu siang 95,8 lux. Pada pengukuran di pagi hari pada Ruang R.G.Lt.1,R.3 di titik 1 (T1) menghasilkan 24,3 lux dan diwaktu siang 99 lux. Pada pengukuran di pagi hari pada Ruang R.G.Lt.1,R.4 di titik 1 (T1) menghasilkan 20,4 lux dan diwaktu siang 83,5 lux.

Berdasarkan perhitungan di Ruang R.D.Lt.1,R.1; R.D.Lt.1,R.2; R.D.Lt.1,R.3; R.G.Lt.1,R.3; R.G.Lt.1,R.4 menunjukan, Ruang R.D.Lt.1,R.1 di titik 1 (T1) menghasilkan 40,9397 lux, Ruang R.D.Lt.1,R.2 di titik 1 (T1) menghasilkan 35,2473 lux, Ruang R.D.Lt.1,R.3 di titik 1 (T1) menghasilkan 16,575 lux, Ruang R.G.Lt.1,R.3 di titik 1 (T1) menghasilkan 15,766 lux, Ruang R.G.Lt.1,R.4 di titik 1 (T1) menghasilkan 15,9578 lux.

Dapat diketahui dari hasil pengukuran dan perhitungan pada Ruang Kuliah Fakultas Teknik Universitas PGRI Palembang bahwa sistem pencahayaannya sangat belum memenuhi standar yang telah ditatapkan oleh SNI 03-6575-2001, hal ini disebabkan oleh karena kurangnya jumlah iluminasi pada lampu atau pencahayaan alami (matahari).

Untuk mencapai kuat penerangan yang diharapkan sebaiknya mengganti lampu dengan lumen $(\mathrm{Lm}) /$ Watt yang lebih besar. Bisa juga dengan menambah jumlah lampu di setiap ruangannya. Atau bisa juga dengan mengganti lampu jenis lain yang lebih efisien yaitu Lampu berjenis LED (Light Emitting Diode).

\section{KESIMPULAN}

1. Dari hasil pengukuran dan perhitungan di atas dapat disimpulkan bahwa kuat penerangan pada bidang kerja (kursi) setiap Ruang Kuliah Fakultas Teknik Universitas PGRI Palembang intensitas penerangan yang ada belum memenuhi standar yang telah ditetapkan oleh Badan Standarisasi Nasional Indonesia (SNI). Dalam hal ini standar minimum pencahayaan buatan yang di rekomendasikan oleh SNI 03-6575-2001 untuk sebuah ruang Kuliah yaitu 250 lux.

2. Kurangnya intensitas penerangan pada bidang kerja (kursi) di setiap Ruang Kuliah Fakultas Teknik Universitas PGRI Palembang karena kurangnya pencahayaan lampu yang terpasang.

\section{DAFTAR PUSTAKA}

1. Nurdiana, N. (2017). EVALUASI KUAT PENERANGAN DI RUANG PRAKTIKUM LABORATORIUM TERPADU UNIVERSITAS PGRI PALEMBANG. Jurnal Ampere, 2(2), 121-127.

2. Muhaimin, 2001. Teknologi Pencahayaan. Penerbit Reflika Aditama, Bandung, Indonesia.

3. SNI 03-6575-2001, Tata Cara Perancangan Sistem Pencahayaan Buatan pada Bangunan Gedung.

4. Watkins, A.J, Parton, R.K., Perhitungan Instalasi Listrik 2, Jakarta: Penerbit Erlangga.

5. Lib. Unnes. Ac.id oleh IF Rhomadhon, 2009

6. Harten, P. Van \& Setiawan, E. 1995. Instalasi Listrik Arus Kuat 2. Binacipta, Bandung, Indonesia.

7. Linsley, Trevor. 2004. Instalasi Listrik Tingkat Lanjut 3. Erlangga, Jakarta, Indonesia. 